\title{
Development and Validation of Search Filters to Identify Articles on Family Medicine in Online Medical Databases
}

\author{
David H.J. Pols, MD, MSc ${ }^{1}$ \\ Wichor M. Bramer, BSc ${ }^{2}$ \\ Patrick J.E. Bindels, MD, $P b D^{1}$
}

Floris A. van de Laar, $M D, P b D^{3}$

Artbur M. Bobnen, MD, $P b D^{1}$

'Department of Family Medicine, Erasmus MC, University Medical Center Rotterdam, Rotterdam, The Netherlands

${ }^{2}$ Medical Library, Erasmus MC, University Medical Center Rotterdam, Rotterdam, The Netherlands

${ }^{3}$ Department of Primary and Community Care, Radboud University Medical Center, Nijmegen, The Netherlands

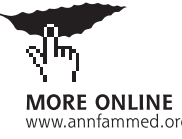

Conflicts of interest: authors report none.

\section{CORRESPONDING AUTHOR}

David H. J. Pols, MD, MSc

Department of Family Medicine

Erasmus MC, University Medical Center

Rotterdam

PO Box 2040

3000 CA Rotterdam, The Netherlands

d.pols@erasmusmc.nl

\begin{abstract}
Physicians and researchers in the field of family medicine often need to find relevant articles in online medical databases for a variety of reasons. Because a search filter may help improve the efficiency and quality of such searches, we aimed to develop and validate search filters to identify research studies of relevance to family medicine. Using a new and objective method for search filter development, we developed and validated 2 search filters for family medicine. The sensitive filter had a sensitivity of $96.8 \%$ and a specificity of $74.9 \%$. The specific filter had a specificity of $97.4 \%$ and a sensitivity of $90.3 \%$. Our new filters should aid literature searches in the family medicine field. The sensitive filter may help researchers conducting systematic reviews, whereas the specific filter may help family physicians find answers to clinical questions at the point of care when time is limited.
\end{abstract}

Ann Fam Med 2015;13:364-366. doi: 10.1370/afm.1780.

\section{INTRODUCTION}

lthough many physicians use online medical databases to obtain
biomedical information for clinical practice, the enormous volume
and diversity of the available literature makes searching a challenging process. Lack of time and skills, as well as a clear preference for asking an expert colleague or consulting a print source, are considered barriers to the use of online databases. ${ }^{1,2} \mathrm{~A}$ specific search filter might enhance the retrieval of relevant articles at the point of care by the physician. On the other hand, researchers completing a systematic review will need a sensitive search filter to avoid missing relevant articles. We conducted a study to develop and validate objective, sensitive, and specific search filters, applicable in frequently used databases, to identify studies that are conducted in or that apply or refer to family medicine and general practice settings.

\section{METHODS}

\section{Definition of Family Medicine}

A clear definition relevant to family medicine/general practice is needed to develop an efficient and objective search filter. The European branch of the World Organization of National Colleges, Academies and Academic Associations of General Practitioners/Family Physicians (WONCA Europe) provides a consensus statement in which they define the discipline of family medicine/general practice. ${ }^{3}$ On the basis of a short questionnaire that was sent to colleagues worldwide using the e-mail list of the Cochrane Primary Healthcare Field, we learned that many share this definition (Supplemental Appendix 1, available at http://www.annfammed.org/ content/13/4/364/suppl/DC1). The respondents indicated, however, that 2 additional aspects should be taken into account. First, an inpatient hospital setting should explicitly be excluded. Second, one should be aware of the difference between primary care and family medicine/general practice. Respondents often regarded primary care as an umbrella term that 
includes family medicine/general practice, but could also include (among others) midwifery, psychology, and physiotherapy.

We considered any research article relevant to general practice if the article explicitly indicated the research was completed in a family medicine/general practice setting as defined by WONCA, excluded inpatient hospital care, and focused specifically on family medicine/general practice. Research articles that had family medicine/general practice as their research domain were also considered relevant (eg, research on the efficiency of general practices).

\section{Creating and Validating Sensitive and Specific Filters}

Two independent reviewers (D.H.J.P. and F.A.L.) classified 1,000 articles as being relevant or irrelevant to family medicine, creating a reference standard. From this reference standard, we derived a term identification set and a development set. Using specialized software, candidate filter terms and phrases (combination of words) were derived objectively from the term identification set based on frequency of occurrence. Sensitive and specific filters were created in the development set by combining these candidate terms and phrases to obtain optimal performance. The derived filters were then validated on the reference set and on 2 external validation sets (Supplemental Appendix, pages 4 and 5). Finally, we compared the performance of the filters with that of other family medicine/general practice filters.

\section{RESULTS}

We used the above methodology to construct strings of sensitive and specific filters and translated these filters for use in different databases (Table 1). In the validation process, the sensitive filter had an overall sensitivity of $96.8 \%$ (range $=95.4 \%$ to $100 \%$ ), with an adequate overall specificity of $74.9 \%$ (range $=69.2 \%$ to $89.5 \%$ ). For the specific filter, the overall specificity was $97.4 \%$ (range $=94.8 \%$ to $99.3 \%$ ), with an adequate overall sensitivity of $90.3 \%$ (range $=83.9 \%$ to $96.0 \%$ ). Both the sensitive and the specific filters performed better than other recently published filters on the same topic (Table 2). ${ }^{4-7}$

\section{DISCUSSION}

We created and extensively validated 2 search filters for family medicine, both with good sensitivity and specificity.

Our specific filter was developed to help family physicians find answers to clinical questions at the point of care when time is limited. It provides the physician with references that are relevant, but with a small risk of missing articles. If an answer to the question is not found using the specific filter, the sensitive filter could be used next.

Our sensitive filter can also be used by researchers conducting a systematic review. It provides considerable efficiency. For example, we constructed a search string for a systematic review on atopic disorders in children through which 3,972 publications were found. If our sensitive filter had been applied, the number of relevant articles could have been limited to 1,478 . In this example, no relevant articles were missed. Comparing our sensitive filter with the common practice of search strategies used when conducting, for example, Cochrane systematic reviews, all tested literature searches showed a lack of good sensitivity (see online Supplemental Appendix). Thus, it can be assumed that relevant references were missed in these reviews, which might have been found when applying our sensitive search filter.

\section{Table 1. Our Filters for Family Medicine/General Practice Translated for Different Databases}

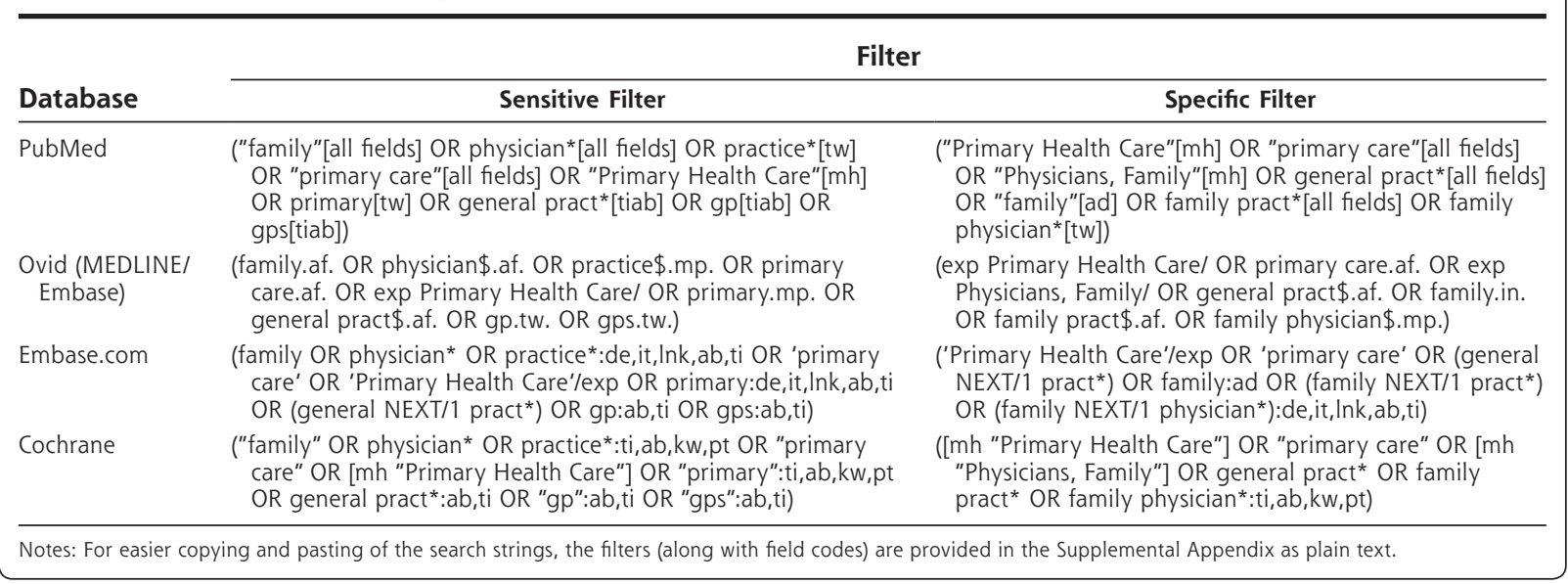


Table 2. Performance of Our Filters Compared With That of Other Published Filters for Family Medicinel General Practice

\begin{tabular}{|c|c|c|c|c|c|c|c|c|}
\hline \multirow[b]{2}{*}{$\begin{array}{l}\text { Standard } \\
\text { Used }^{\mathrm{a}}\end{array}$} & \multicolumn{2}{|c|}{ Our Filters } & \multicolumn{6}{|c|}{ Other Published Filters } \\
\hline & $\begin{array}{l}\text { Sensitive } \\
\text { Filter }\end{array}$ & $\begin{array}{l}\text { Specific } \\
\text { Filter }\end{array}$ & $\begin{array}{c}\text { Primary } \\
\text { Health Care } \\
\text { Search Filter }\end{array}$ & $\begin{array}{l}\text { Jelercic } \\
\text { et } \mathrm{al}^{7}\end{array}$ & $\begin{array}{c}\text { Glanville } \\
\text { et } \mathrm{al}^{6}\end{array}$ & $\begin{array}{l}\text { Gill et al }^{5} \\
\text { High } \\
\text { Sensitivity }\end{array}$ & $\begin{array}{l}\text { Gill et al }{ }^{5} \\
\text { Balanced }\end{array}$ & $\begin{array}{l}\text { Gill et al } \\
\text { High } \\
\text { Specificity }\end{array}$ \\
\hline \multicolumn{9}{|l|}{ Review } \\
\hline Sensitivity, \% & 100.0 & 90.7 & 81.4 & 46.5 & 95.3 & 95.3 & 93.0 & 88.4 \\
\hline Specificity, \% & 69.2 & 97.9 & 99.0 & 94.4 & 77.0 & 61.0 & 99.1 & 99.5 \\
\hline \multicolumn{9}{|l|}{ Reference } \\
\hline Sensitivity, \% & 95.4 & 83.9 & 65.9 & 78.0 & 84.3 & 85.9 & 68.9 & 57.0 \\
\hline Specificity, \% & 69.5 & 94.8 & 96.3 & 89.4 & 89.4 & 47.6 & 96.7 & 98.6 \\
\hline \multicolumn{9}{|l|}{ Questionnaire } \\
\hline Sensitivity, \% & 97.4 & 96.0 & 81.4 & 87.4 & 97.0 & 96.2 & 92.2 & 78.0 \\
\hline Specificity, \% & 89.5 & 99.3 & 99.0 & 97.8 & 96.1 & 84.9 & 99.4 & 99.8 \\
\hline \multicolumn{9}{|l|}{ Overall } \\
\hline Sensitivity, \% & 96.8 & 90.3 & 80.8 & 81.9 & 92.3 & 91.9 & 83.7 & 70.9 \\
\hline Specificity, \% & 74.9 & 97.4 & 98.3 & 94.3 & 83.6 & 65.0 & 98.7 & 99.4 \\
\hline
\end{tabular}

Our filters do not use the Boolean operators AND or NOT, but combine single search terms and phrases in an OR relationship. In our methodology, however, phrases were already separately identified as combinations of words in an AND manner that could potentially discriminate between those that are relevant to family medicine/general practice and those that are not. For example "primary health care" was identified in this way. These 3 words are combined in an AND manner, but the quotes also demand they be in this specific order. Using an objective method, the developed filters did not always produce phrases that one would expect, such as "family physician." Our objective method, however, suggested the single words "family" and "physician" to be more distinctive. Finally, we rejected using NOT because its use would carry a substantial risk of excluding relevant articles.

We conclude that the described objective method results in highly sensitive and specific filters for family medicine that should be helpful to researchers and clinicians using online medical databases to obtain biomedical information.

To read or post commentaries in response to this article, see it online at http://www.annfammed.org/content/13/4/364.

Key words: family medicine; general practice; search filters; information storage and retrieval; bibliographic databases

Submitted August 7, 2014; submitted, revised, February 9, 2015; accepted February 22, 2015.
Acknowledgments: The authors thank Heleen Moed, Dahri Al Rashad, Elvira van Alphen, and Youssou Gueye for their assistance in the preparation of this study.

Supplementary materials: Available at http://www.AnnFamMed. org/content/13/4/364/suppl/DC1/

\section{References}

1. Younger P. Internet-based information-seeking behaviour amongst doctors and nurses: a short review of the literature. Health Info Libr J. 2010;27(1):2-10.

2. Davies K, Harrison J. The information-seeking behaviour of doctors: a review of the evidence. Health Info Libr J. 2007;24(2):78-94.

3. The European definition of general practice/family medicine. WONCA Europe Web site. http://www.woncaeurope.org/sites/ default/files/documents/Definition\%203rd\%20ed\%202011\%20 with\%20revised\%20wonca\%20tree.pdf. Updated 2011. Accessed Mar 2, 2014

4. Brown L, Carne A, Bywood P, et al. Facilitating access to evidence: Primary Health Care Search Filter. Health Info Libr J. 2014; 31(4): 293-302.

5. Gill PJ, Roberts NW, Wang KY, Heneghan C. Development of a search filter for identifying studies completed in primary care. Fam Pract. 2014;31(6):739-745.

6. Glanville J, Kendrick T, McNally R, Campbell J, Hobbs FD. Research output on primary care in Australia, Canada, Germany, the Netherlands, the United Kingdom, and the United States: bibliometric analysis. BMJ. 2011;342:d1028.

7. Jelercic S, Lingard H, Spiegel W, Pichlhöfer O, Maier M. Assessment of publication output in the field of general practice and family medicine and by general practitioners and general practice institutions. Fam Pract. 2010;27(5):582-589. 